\title{
Evaluating the Impacts of Generation Capacity Cycles in New Zealand
}

\author{
Thahirah Syed Jalal and Pat Bodger
}

\begin{abstract}
Since the commencement of the Electricity Market (NZEM) in October 1996, generation expansion in New Zealand is made based on profit anticipation from the wholesale electricity spot price rather than through coordinated planning. This has caused boom and bust cycles in the generation capacity. Energy shortages occurred in 2001, 2003 and 2008. A new model based on System Dynamics (SD) is developed to study these cycles. Its results are compared to the results of the Generation Expansion Model (GEM), developed by the New Zealand Electricity Commission and published in the Statement of Opportunity 2008 (SOO2008). The model is able to identify some capacity cycles that are likely to happen in the future. The analysis is then extended to evaluate whether the cycles will result in energy shortages. The SD model shows that under some future scenarios, New Zealand is susceptible to electricity shortages due to the bust periods in the capacity cycles.
\end{abstract}

Index Terms-Deregulation, investment cycles, market instability modeling, power market dynamics, reliability

\section{NOMENCLATURE}

Carbon Capture Storage (CCS), Combined Cycle Gas Turbine (CCGT), Generation Expansion Model (GEM), Energy Capacity Margin (ECM), Electricity Commission (EC), Electricity Supply Industry (ESI), Electric Vehicle (EV), Integrated Gasification Combined Cycle (IGCC), Long Range Marginal Costs (LRMC), Market Development Scenario (MDS), Mixed Integer Programming (MIP), New Zealand Electricity Market (NZEM), Open Cycle Gas Turbine (OCGT), Statement of Opportunity (SOO), System Dynamics (SD)

\section{INTRODUCTION}

$\mathrm{T}_{\mathrm{f}}^{\mathrm{H}}$ HE restructuring of the electricity supply industry (ESI) from 1988 in New Zealand has brought several changes to the way infrastructures are planned and expanded. Since the commencement of the Electricity Market (NZEM) in October 1996, generation expansion in New Zealand is made based on profit assessments on wholesale electricity sales rather than through coordinated planning.

It has been shown in some studies [1-5] that deregulation of the electricity industry causes bust and boom cycles of generation capacity due to investment uncertainties. Initially power generators are uncertain on whether they should build a

This work is done in the Electrical Power Engineering Centre (EPECentre), University of Canterbury, New Zealand. new power plant, as that may affect the spot price in the power market and hence affect their profit returns. The lack of new capacity then reduces the margin between electricity supply and demand and pushes the prices up. Then substantial overbuilding occurs during high market prices because most generators decide to build new power stations at around the same time [6]. These bust and boom patterns have been observed in the United States [1, 3], European countries [4, 5] and also New Zealand [6].

Fig. 1 shows that the installed generation in New Zealand declined for the first time in 1988 before steadily picking up again in 2000, despite the continuous growth of electricity demand within that duration [7]. Electricity shortages occurred in July 2001, March 2003 and March 2008. The shortages occurred due to dry weather resulting in low hydro lake levels. New Zealand has always been highly reliant on hydro resources but such shortages did not occur prior to the restructuring due to coordinated efforts in managing the country's resources. These shortages raise questions as to whether the New Zealand Electricity Market (NZEM) is sufficient to provide adequate capacity to meet the demand.

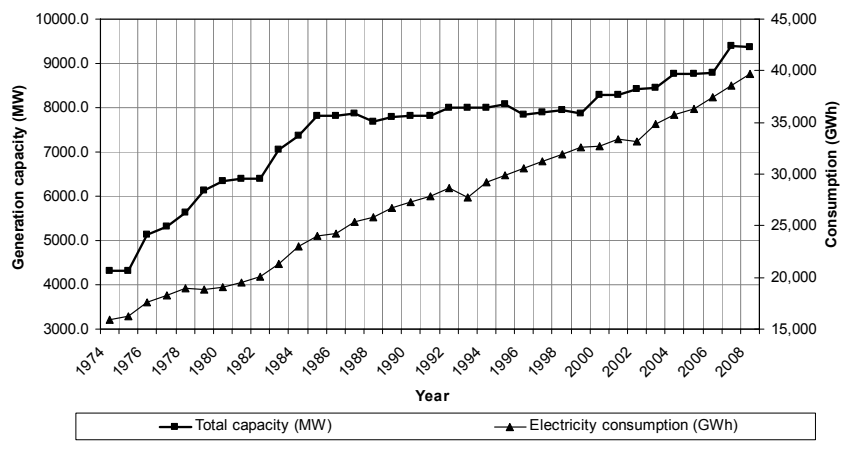

Fig. 1. Installed generation capacity in New Zealand from 1974-2008

\section{BACKGROUND AND OBJECTIVES}

Under part F of the Electricity Governance Rules 2003, the Statement of Opportunity (SOO) is published periodically by the New Zealand Electricity Commission. The purpose of the SOO is "to enable the identification of potential opportunities for efficient management of the grid, including investment in upgrades and transmission alternatives" [8]. The Statement of Opportunity 2008 (SOO2008) considers five different future scenarios as elaborated in Table I. Under the various scenarios, the document provides electricity demand forecasts 
up to the year 2050 and tentative schedules of power plants up to the year 2040. However, the dry-year dispatch is not explicitly addressed in the document "as it is expected that market participants would effectively manage hydro storage using the capability of the grid to transfer power from North to South during periods of low demand" [8].

The SOO2008 uses a model known as the Generation Expansion Model (GEM) for its analyses. The model is formulated as a mixed integer programming (MIP) problem, written using the GAMS [9] optimisation software with a CPLEX solver. The model takes into account cost minimisation, future demand, HVDC link energy transfer and hydro inflows in formulating the build schedules. However, the model does not include the effects of market supply and demand interaction in developing the schedules.

TABLE I

SOO2008 GENERATION AND DEMAND ASSUMPTIONS FOR FIVE DIFFERENT FUTURE SCENARIOS [8]

\begin{tabular}{|c|c|c|}
\hline Scenario & Generation assumptions & Demand assumptions \\
\hline $\begin{array}{l}\text { Sustainable } \\
\text { Path (MDS1) }\end{array}$ & $\begin{array}{l}\text { - High renewable energy } \\
\text { penetration backed by thermal } \\
\text { peakers } \\
\text { - New energy sources are } \\
\text { brought on stream in the late } \\
2020 \text { s and 2030s }\end{array}$ & 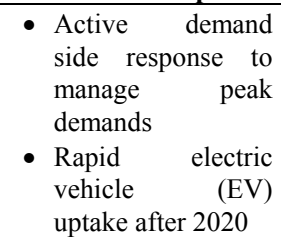 \\
\hline $\begin{array}{l}\text { South Island } \\
\text { Surplus } \\
\text { (MDS2) }\end{array}$ & $\begin{array}{l}\text { - Renewable development } \\
\text { proceeds at a moderate pace, } \\
\text { with all existing gas-fired } \\
\text { power stations remaining in } \\
\text { operation until after } 2030 \\
\text { - Wind and hydro generation } \\
\text { increase considerably } \\
\text { supplemented by thermal } \\
\text { peakers }\end{array}$ & $\begin{array}{l}\text { - The demand-side } \\
\text { remains relatively } \\
\text { uninvolved. }\end{array}$ \\
\hline $\begin{array}{l}\text { Medium } \\
\text { Renewables } \\
\text { (MDS3) }\end{array}$ & $\begin{array}{l}\text { - Geothermal development } \\
\text { playing an important role } \\
\text { supplemented by thermal } \\
\text { plants } \\
\text { - The coal-fired units at Huntly } \\
\text { transition through dry-year } \\
\text { reserve to total closure }\end{array}$ & $\begin{array}{ll}\text { - Tiwai smelter } & \text { is } \\
\text { assumed } & \text { to } \\
\text { decommission } & \text { in } \\
\text { the mid-2020s. } & \end{array}$ \\
\hline $\begin{array}{l}\text { Demand-side } \\
\text { Participation } \\
\text { (MDS4) }\end{array}$ & $\begin{array}{l}\text { - New coal- and lignite-fired } \\
\text { plants are constructed after } \\
2020 \\
\text { - Geothermal resources are } \\
\text { developed. } \\
\text { - Little new hydro can be } \\
\text { consented } \\
\text { - Huntly Power Station remains } \\
\text { in full operation until } 2030\end{array}$ & $\begin{array}{l}\text { - Demand-side } \\
\text { participation } \\
\text { becomes important } \\
\text { EV uptake is high, } \\
\text { and vehicle-to-grid } \\
\text { technology is used } \\
\text { to manage peaks } \\
\text { and provide } \\
\text { ancillary services. }\end{array}$ \\
\hline $\begin{array}{l}\text { High Gas } \\
\text { Discovery } \\
\text { (MDS5) }\end{array}$ & $\begin{array}{l}\text { - Major new indigenous gas } \\
\text { discoveries keep gas prices } \\
\text { low to } 2030 \text { and beyond } \\
\text { - Some existing thermal power } \\
\text { stations are replaced by new, } \\
\text { more efficient gas-fired plants } \\
\text { - New CCGTs and gas-fired } \\
\text { peakers are built }\end{array}$ & $\begin{array}{l}\text { - The demand-side } \\
\text { remains relatively } \\
\text { uninvolved. }\end{array}$ \\
\hline
\end{tabular}

The authors have developed a system dynamics (SD) model to study the generation capacity issue in New Zealand and made projections to investigate whether capacity cycles will continue to happen in New Zealand. The results show that under some scenarios, capacity cycles will continue to occur in the future and this is most probably due to the current energy market structure [10]. Comparisons of the resulting capacity cycles against the steady capacity growth projected in the SOO2008 has been made [10] and elaborated in Section VI. The model is extended to evaluate whether the cycles will cause energy shortages in the future.

\section{SD MODEL DESCRIPTIONS}

The SD model used in the analysis is summarised in this section.

\section{A. Model features}

SD is a type of behavioural simulation model. It is a descriptive modeling method based on explicit recognition of feedback and time lags [11, 12]. Rather than model the electricity supply and demand using the concept of cause and effect, SD captures a more realistic dynamic relationship between them by incorporating feedbacks. The main interacting loops in the SD model are shown in Fig. 2. The components in the loops interact dynamically and influence each other's behaviour. The spot market price influences the investment decisions as what happens in the NZEM. The price is determined by the SD model from the difference between the supply and demand.

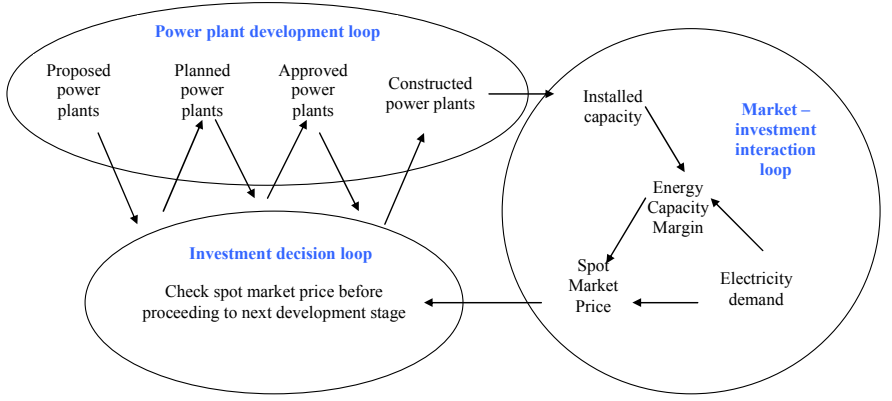

Fig. 2. The three main loops in the SD model that captures market interaction with power plant development

Before allowing the power plants to proceed into different development phases, their Long Range Marginal Cost (LRMC) is compared against the spot market price. They are allowed to proceed into the next development phase only if the spot market price is more than the plant's LRMC. This investment decision process is summarized in Fig. 3. 


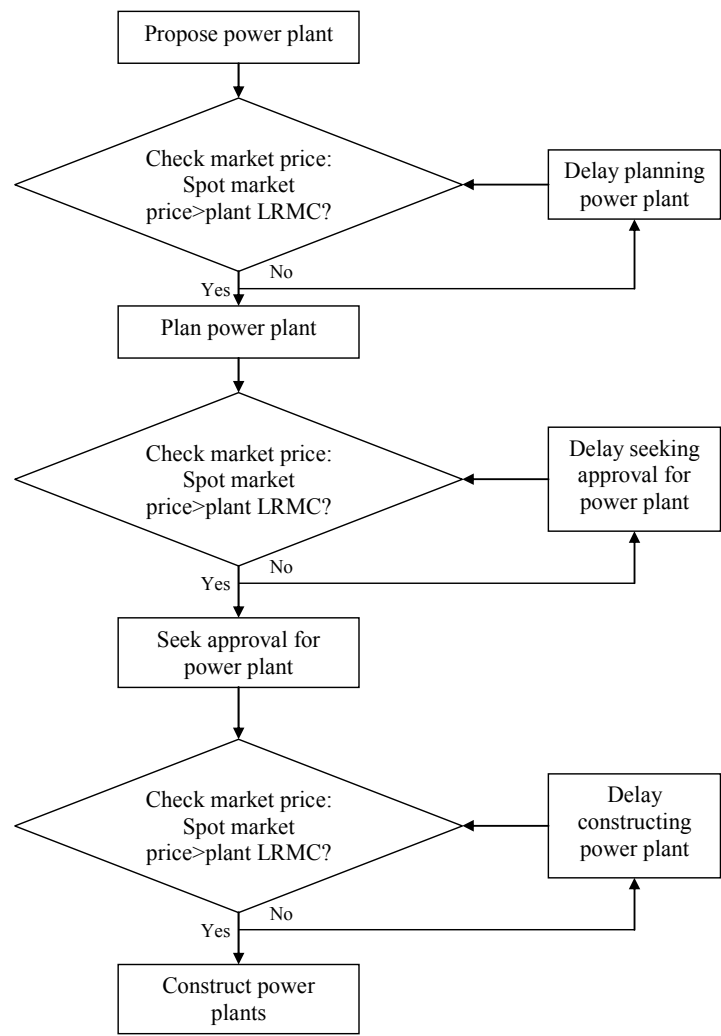

Fig. 3. Investment decisions based on the NZEM model

When a new capacity gets commissioned, the installed capacity increases. Depending on the gap between the supply and demand, the spot market price is adjusted accordingly. A big gap pushes up the price and vice versa. The adjusted price will then influence when a new plant comes in as it is only allowed to go through a development stage when its LRMC is exceeded by the price.

\section{B. Model inputs}

The SD simulations are run from 2010 till 2040, similar to the GEM model simulations for the SOO2008. To provide a fair comparison, the SD model uses the same inputs and assumptions as the GEM model for the SOO2008. These inputs are the demand forecast until 2050 (Fig. 4) under each scenario and the plants' LRMC and plant availability factors (Table II and III). Fig. 4 shows the annual total demand, but the model takes the data monthly to include seasonal demand variation. The LRMC for thermal plants are higher due to higher gas prices and carbon tax.

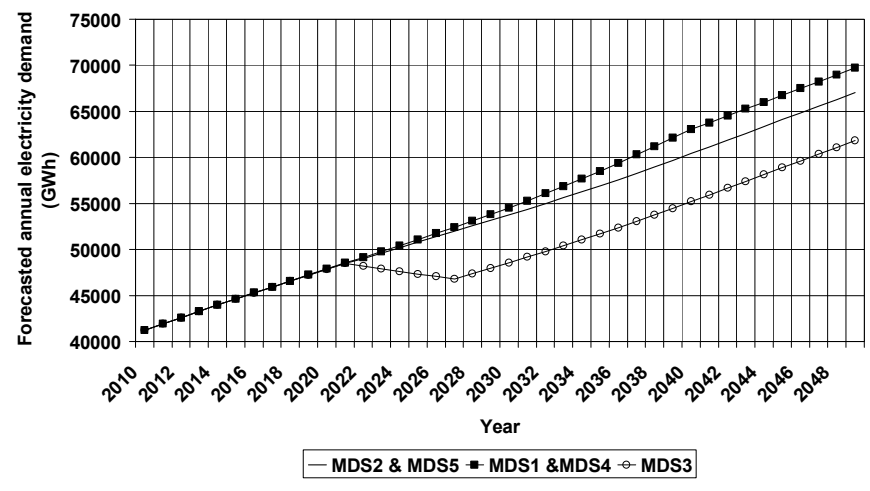

Fig. 4. Demand input data for the different projected scenarios

TABLE II

LRMC AND PLANT AVAILABILITY FACTORS FOR NON THERMAL PLANTS

\begin{tabular}{|l|c|c|}
\hline \multicolumn{1}{|c|}{ Plant types } & $\begin{array}{c}\text { Plant } \\
\text { availability } \\
\text { factor }(\%)\end{array}$ & LRMC (\$/MWh) \\
\hline Hydro & 50 & 85 \\
\hline Geothermal & 90 & 80 \\
\hline Cogeneration & 70 & 130 \\
\hline Marine & 45 & 125 \\
\hline Wind & 45 & 80 \\
\hline
\end{tabular}

TABLE III

LRMC AND PLANT AVAILABILITY FACTORS FOR THERMAL PLANTS

\begin{tabular}{|l|c|c|c|}
\hline \multicolumn{1}{|c|}{ Plant types } & $\begin{array}{c}\text { Plant } \\
\text { availa- } \\
\text { bility } \\
\text { factor } \\
\mathbf{( \% )}\end{array}$ & $\begin{array}{c}\text { LRMC } \\
\mathbf{( \$ / M W h )} \\
-\mathbf{g a s} \text { at } \\
\mathbf{\$ 7 / G J , ~ n o} \\
\mathbf{c a r b o n} \\
\text { charge }\end{array}$ & $\begin{array}{c}\text { LRMC } \\
\mathbf{( \$ / M W h )} \\
- \text { gas at } \\
\mathbf{\$ 1 0 / G J} \\
\mathbf{c a r b o n} \text { at } \\
\mathbf{\$ 3 0 / t o n n e}\end{array}$ \\
\hline $\begin{array}{l}\text { Combined Cycle Gas Turbine } \\
\text { (CCGT) }\end{array}$ & 90 & 75 & 107 \\
\hline Open Cycle Gas Turbine (OCGT) & 20 & 215 & 261 \\
\hline Coal & 90 & 85 & 111 \\
\hline $\begin{array}{l}\text { Integrated Gasification Combined } \\
\text { Cycle (IGCC) with Carbon Capture } \\
\text { Storage (CCS) }\end{array}$ & 90 & 119 & 123 \\
\hline
\end{tabular}

The model also uses the power plant schedules proposed by the SOO2008 as inputs to the power plant development loop. The scheduled plants are given a certain lead time and allocated different development phase durations depending on the plant type, as shown in Table IV.

TABLE IV

Plant Lead Time and Development Phase Duration

\begin{tabular}{|l|c|c|c|c|}
\hline Plant type & $\begin{array}{l}\text { Plant } \\
\text { lead time } \\
\text { (year) }\end{array}$ & $\begin{array}{l}\text { Planning } \\
\text { duration } \\
\text { (year) }\end{array}$ & $\begin{array}{l}\text { Approval } \\
\text { time } \\
\text { (year) }\end{array}$ & $\begin{array}{l}\text { Construction } \\
\text { duration } \\
\text { (year) }\end{array}$ \\
\hline Hydro & 5 & 1 & 1 & 3 \\
\hline Coal / IGCC & 4 & 1 & 1 & 2 \\
\hline CCGT & 3 & 0.5 & 0.5 & 2 \\
\hline OCGT & 2 & 0.5 & 0.5 & 1 \\
\hline Wind & 3 & 1 & 1 & 1 \\
\hline Geothermal & 3 & 1 & 1 & 1 \\
\hline Cogeneration & 3 & 1 & 1 & 1 \\
\hline
\end{tabular}




\section{ENERGY SHORTAGES EVALUATION}

In the last thirty years, New Zealand has been successful in meeting peak electricity demands (instantaneous power demand in MW) by having active demand side participation. However, the system has become energy constrained, especially during dry winter years where low hydro lake levels caused the supply to become insufficient to meet the energy demand (in GWh). To evaluate energy supply adequacy, a variable known as the energy capacity margin $(\mathrm{ECM})$ is introduced. It is defined as:

$$
\mathrm{ECM}=\frac{\text { Available energy supply }- \text { Energy demand }}{\text { Energy demand }}
$$

The available energy supply is calculated from the installed capacity and the plant availability factor where:

$$
\begin{aligned}
& \text { Available energy supply }=\text { Installed capacity x Plant } \\
& \text { availability factor }
\end{aligned}
$$

The energy demand is the load demand in GWh. The plant availability factors are shown in Tables II and III. The ECM is calculated on a monthly basis to take into account seasonal variations in electricity demand as winter consumptions in New Zealand are higher due to space heating.

\section{SD Model Results \& Discussions}

The SD model results are compared with the SOO2008 projections for the five future scenarios. The corresponding ECMs are also provided.

\section{A. Sustainable Path (MDS1)}

Fig. 5 shows that the SD model results lag behind the SOO2008 proposed schedule. This is due to investors waiting for the right spot market price before investing to allow for maximum profit. Capacity cycles are not obvious as the capacity dips are only for several months. The corresponding ECM (Fig. 6) remains positive but dips low around 2020 and 2022. If a dry year occurs during these years, a shortage may occur. The higher ECMs from 2034 onwards indicate that the supply is adequate and no new plants are required to meet the demand. Hence, by 2040, the SD model generates less installed capacity compared to the GEM model.

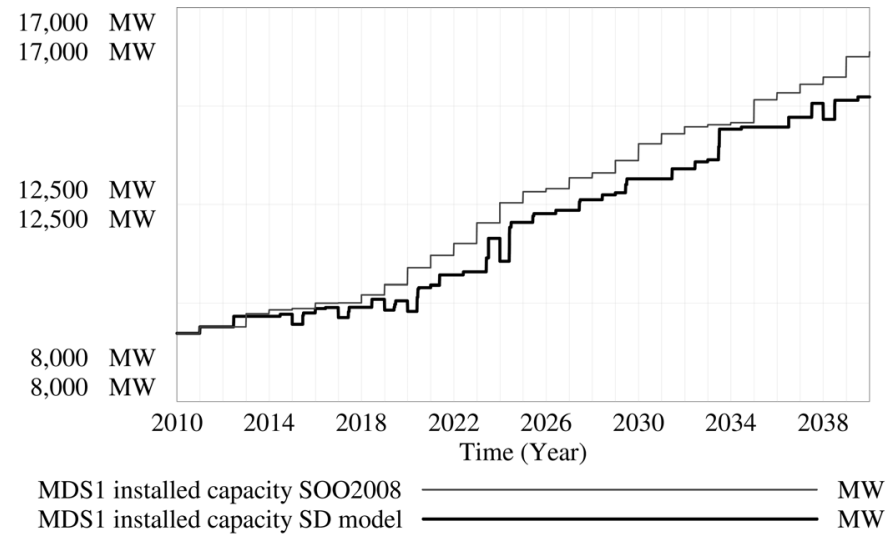

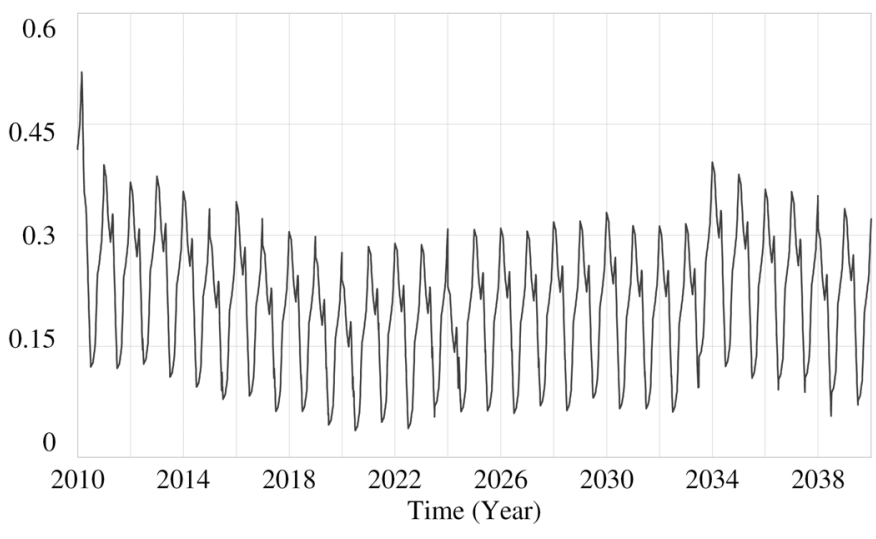

Fig. 6. ECM for the SD model results for MDS1

\section{B. South Island Surplus (MDS2)}

Under MDS2, the differences between the SD model and SOO2008 results widen throughout the years (Fig. 7). The gap between the two results for MDS2 is bigger than for MDS1 since the demand grows at a slower pace after 2022 (see Fig. 4). The SD model predicts a bust period of around 2 years after 2038. The ECM (Fig. 8) during that bust period reaches almost zero, indicating a shortage.

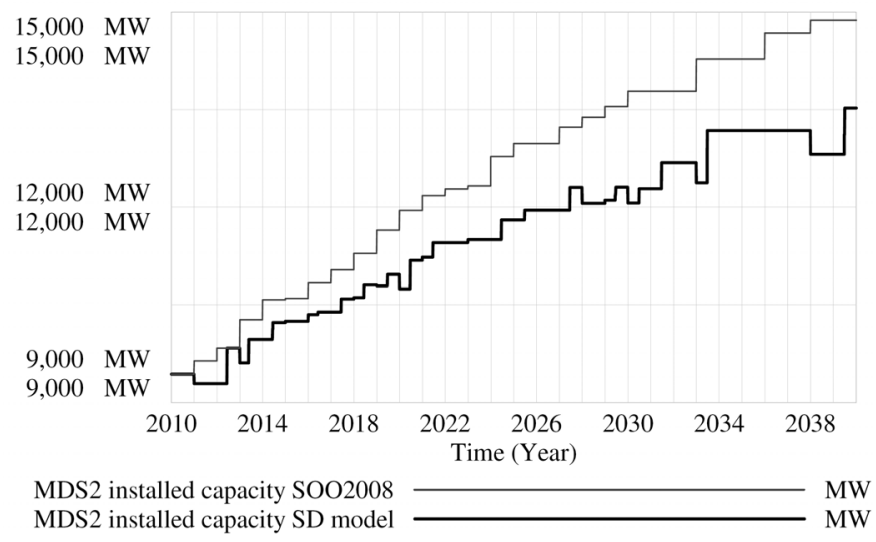

Fig. 7. Results comparison for MDS2

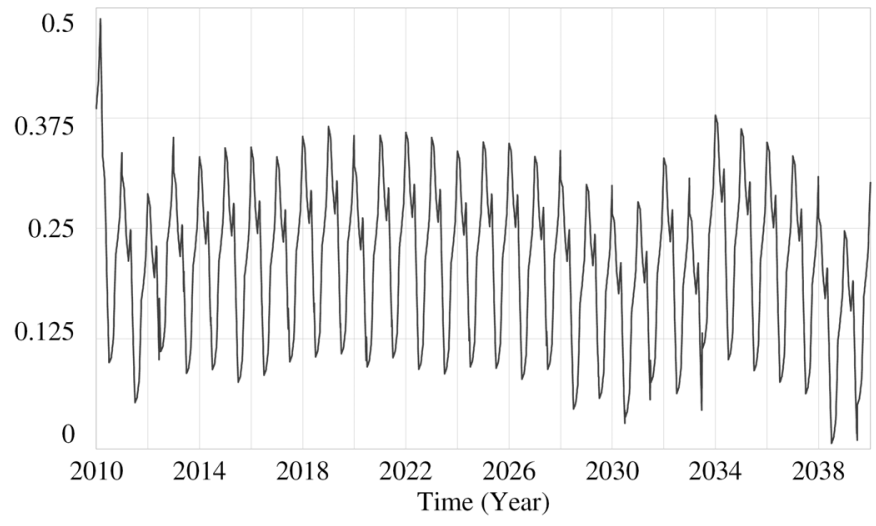

Fig. 8. ECM for the SD model results for MDS2 


\section{Medium Renewables (MDS3)}

The SD model predicts capacity cycles with a bust period of at least 6 years after 2026 (Fig. 9). This is because of the reduced demand due to the Tiwai aluminum smelter being decommissioned after mid 2020 (see Table I and Fig. 4). The reduced demand makes the spot market price low and not conducive for new investments. The bust period results in low ECM around 2033 (Fig. 10). A rapid boom follows afterward when investors try to maximize profits when the spot market price is encouraging again after a long period. The ECM is increased by the new capacities before it starts to decline again in 2036.

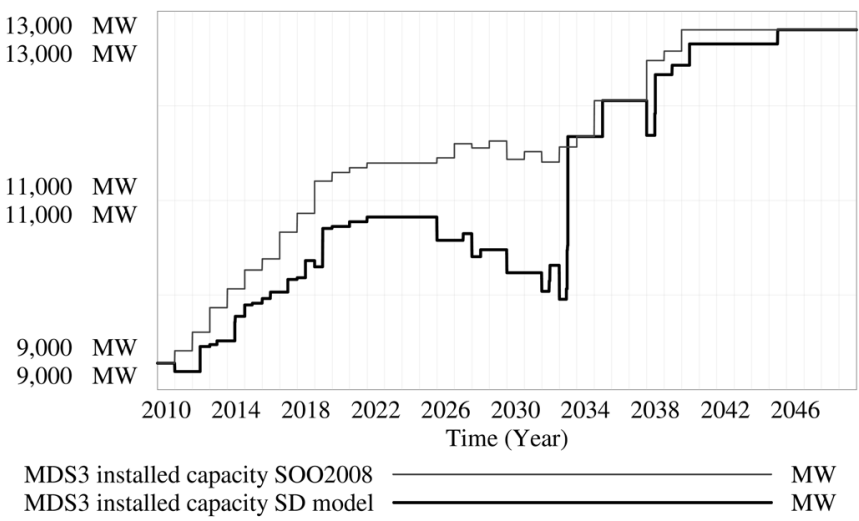

Fig. 9. Results comparison for MDS3

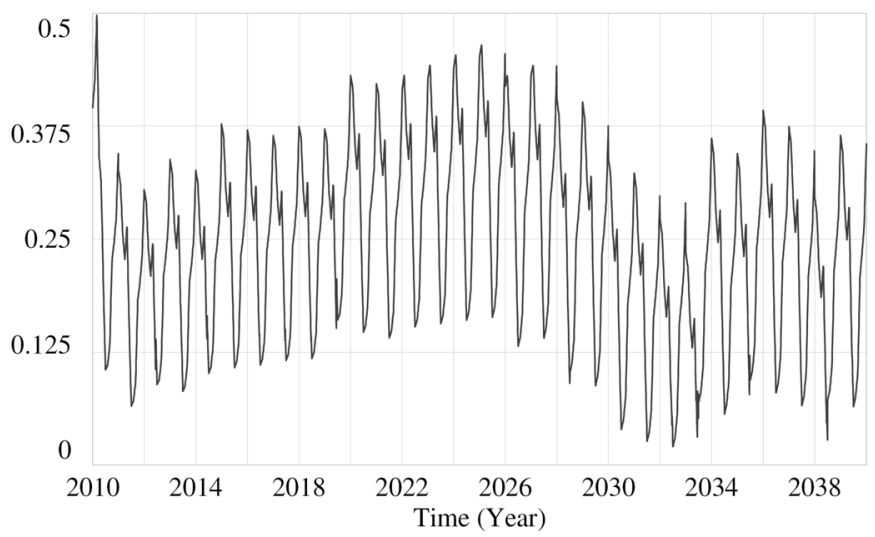

Fig. 10. ECM for the SD model results for MDS3

\section{Demand-side Participation (MDS4)}

Under MDS4, the SD model predicts several cycles of boom and bust trends in the installed capacity (Fig. 11). The boom periods are in 2013-2026, 2030-2032 and 2036-2038 whereas the bust periods are in 2026-2030, 2032-2036 and 2038-2040. The booms after 2030 are steeper due to large capacity lignite and coal plants coming on line. The steady increase in demand causes the ECM to also become cyclic (Fig. 12). Shortages are predicted between 2028 and 2030.

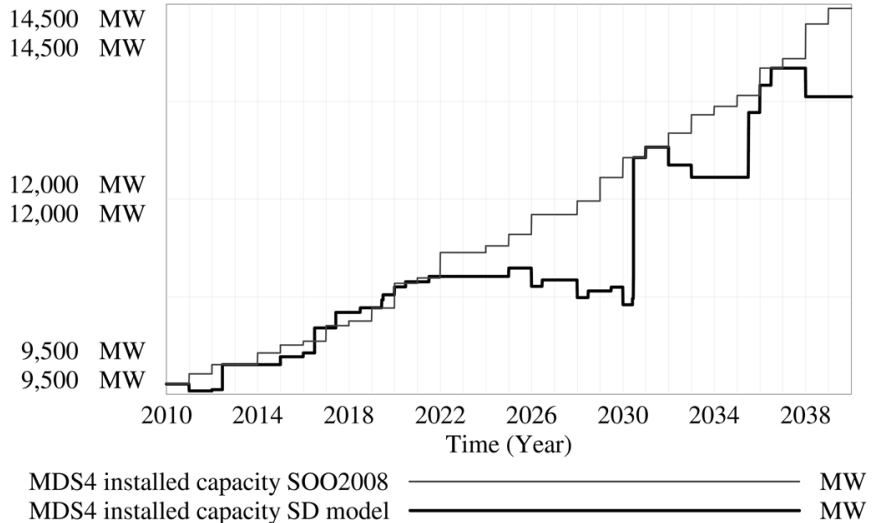

Fig. 11. Results comparison for MDS4

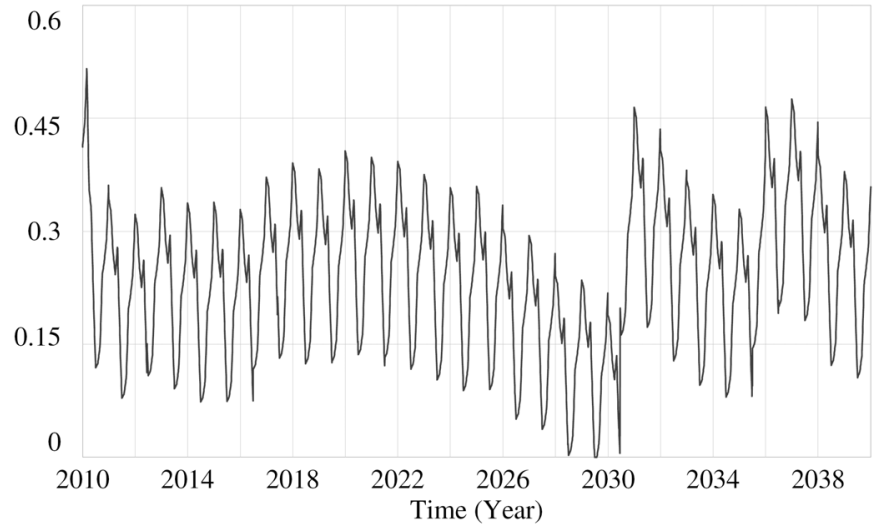

Fig. 12. ECM for the SD model results for MDS4

\section{E. High Gas Recovery (MDS5)}

Under MDS5, the SD model results do not differ much from the SOO2008 results up to the year 2030, as shown in Fig.13. A large disparity is observed between 2030 and 2038. This is because most of the scheduled plants around that time are thermal plants of large capacity and high LRMC. Investors would wait longer for the right market condition before proceeding with the plants. Low ECMs are observed around 2030 and 2038, as shown in Fig. 14.

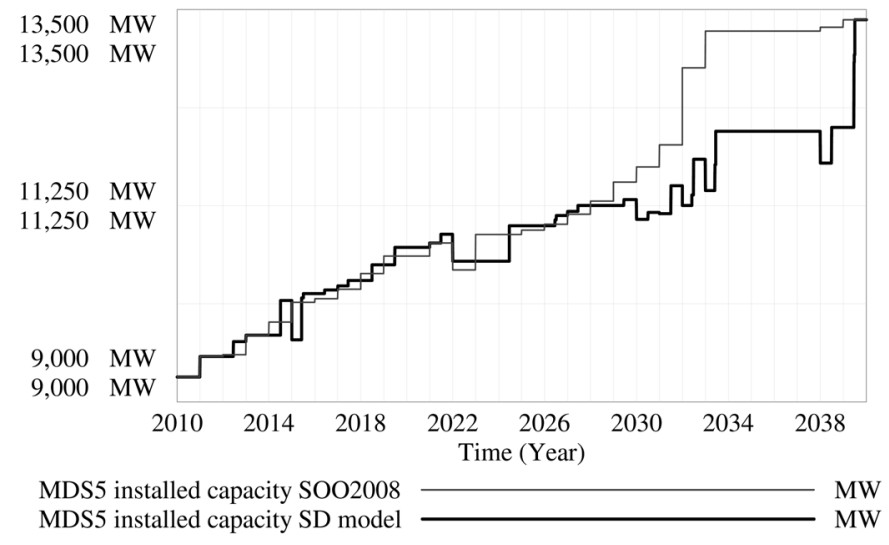

Fig. 13. Results comparison for MDS5 


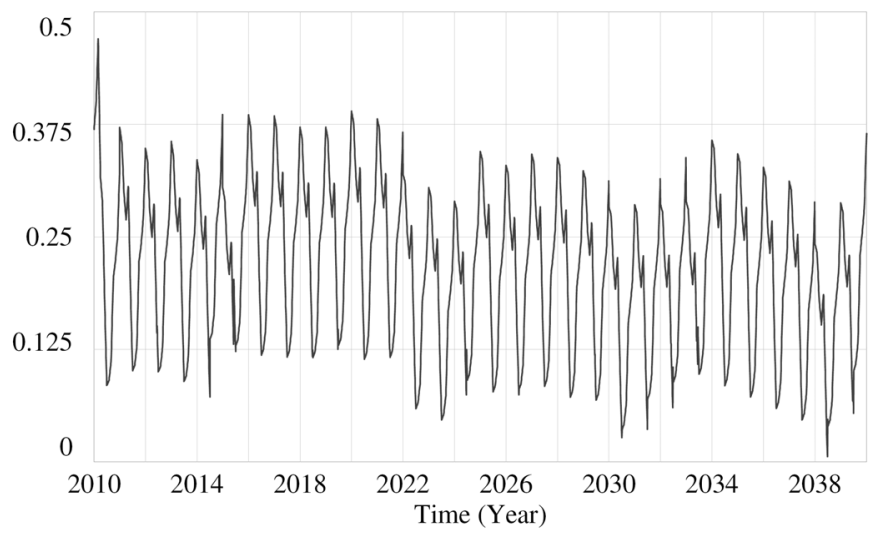

Fig. 14. ECM for the SD model results for MDS5

\section{SUMMARY \& CONCLUSIONS}

Unlike the GEM model, the SD model is able to capture the effect of market interactions with generation investments. Investor's decisions to wait for profitable market conditions can thus be taken into account by the SD model. Therefore the SD model is capable of predicting future generation capacity cycles.

Boom and bust cycles have been observed in other commodity markets such as real estates. However, the cycles in generation capacity are more pronounced when there are power plants of large lumpy capacities, enormous capital investment and long lead time. It can be argued that capacity cycles are normal under a market environment to ensure that investments are made efficiently in meeting demands. However, a severe bust period in the generation capacity may cause severe electricity shortages that can be detrimental to the economy and cause inconvenience to consumers. The variable ECM provides a good indicator in measuring a potential electricity shortage. The resultant ECMs for all five scenarios are summarised in Table $\mathrm{V}$.

TABLE V

RESULTS SUMMARY

\begin{tabular}{|l|l|l|l|l|}
\hline \multicolumn{1}{|c|}{ Scenario } & \multicolumn{3}{|c|}{ ECM statistics } & \multicolumn{2}{|c|}{ Shortage occurs? } \\
\cline { 2 - 5 } & Min & \multicolumn{1}{|c|}{ Max } & Mean & \\
\hline $\begin{array}{l}\text { Sustainable Path } \\
\text { (MDS1) }\end{array}$ & 0.04 & 0.52 & 0.21 & $\begin{array}{l}\text { Possibly in 2020 } \\
\text { and 2022 }\end{array}$ \\
\hline $\begin{array}{l}\text { South Island Surplus } \\
\text { (MDS2) }\end{array}$ & 0 & 0.49 & 0.21 & Yes in 2038 \\
\hline $\begin{array}{l}\text { Medium Renewables } \\
\text { (MDS3) }\end{array}$ & 0.02 & 0.50 & 0.24 & $\begin{array}{l}\text { Possibly in 2032 } \\
\text { and 2038 }\end{array}$ \\
\hline $\begin{array}{l}\text { Demand-side } \\
\text { Participation (MDS4) }\end{array}$ & 0 & 0.52 & 0.24 & $\begin{array}{l}\text { Yes between 2028 } \\
\text { and 2030 }\end{array}$ \\
\hline $\begin{array}{l}\text { High Gas Recovery } \\
\text { (MDS5) }\end{array}$ & 0 & 0.47 & 0.22 & \multicolumn{2}{|l|}{ Yes in 2038 } \\
\hline
\end{tabular}

Since the SD model looks at the input demand data with a monthly resolution, lower ECMs are observed in winter when the demands are high due to space heating. Comparing the ECMs for all five scenarios, shortages are identified for MDS2, 4 and 5. Possible shortages might occur under MDS 1 and 3.

Comparing the results for the different scenarios, the cyclic patterns in installed capacities are more obvious when the plants are large capacity thermal plants with high LRMCs (MDS3 and MDS4). Having more small renewable plants (like in MDS1 and MDS2) produces less cyclic patterns as the LRMCs are lower and hence the profit can be recovered easily with relatively lower spot market prices.

The SD model captures the dynamic interaction between different components in a power market, allowing for more realistic forecasts. The developed model for New Zealand can identify any potential future shortages and provide opportunities for mitigation.

\section{REFERENCES}

[1] A. Ford, "Cycles in competitive electricity markets: a simulation study of the western United States," Energy Policy, vol. 27, pp. 637-658, 1999.

[2] A. Ford, "Waiting for the boom: : a simulation study of power plant construction in California," Energy Policy, vol. 29, pp. 847-869, 2001.

[3] T. Kadoya, et al., "Utilizing System Dynamics Modeling to Examine Impact of Deregulation on Generation Capacity Growth," Proceedings of the IEEE, vol. 93, pp. 2060-2069, 2005.

[4] D. W. Bunn and E. R. Larsen, "Sensitivity of reserve margin to factors influencing investment behaviour in the electricity market of England and Wales," Energy Policy, vol. 20, pp. 420-429, 1992.

[5] F. Lévêque, Competitive electricity markets and sustainability. Cheltenham, UK: Edward Elgar, 2006.

[6] T. S. Jalal and P. Bodger, "The development of a system dynamics model for electricity generation expansion in New Zealand," presented at the 2010 EEA Conference, New Zealand, Christchurch, 2010.

[7] Ministry of Economic Development New Zealand. New Zealand Energy Data File 2009

[8] Electricity Commission, "2008 Statement of Opportunities," ed, 2008.

[9] General Algebraic Modeling System (GAMS). (2010, 26 May 2010). GAMS Homepage. Available: http://www.gams.com/

[10] T. S. Jalal and P. Bodger, "The Development of a System Dynamics Model to Evaluate Electricity Generation Expansion in New Zealand," presented at the 20th Australasian Universities Power Engineering Conference (AUPEC 2010), Christchurch, New Zealand, 2010.

[11] J. W. Forrester, Industrial dynamics. [Cambridge, Mass.]: M.I.T. Press, 1961

[12] J. Sterman, Business dynamics : systems thinking and modeling for a complex world. Boston: Irwin/McGraw-Hill, 2000.

\section{BIOGRAPHIES}

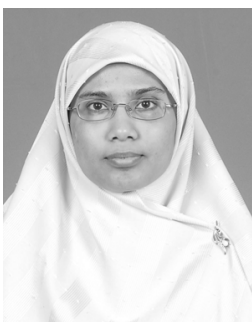

Thahirah Syed Jalal completed an MEng. in Engineering Science from Oxford University, United Kingdom in June 2002, under the scholarship from the main power utility company in Malaysia, Tenaga Nasional Berhad (TNB). She worked in TNB's wholly owned university, Universiti Tenaga Nasional (UNITEN) from July 2002 as a lecturer. Her research and consultancy work there was mainly on electromagnetic fields and sustainable energy. She then pursued her PhD at University of Canterbury, New Zealand. Her thesis is on the development of a System Dynamics (SD) model for generation expansion in New Zealand. Upon completion of the PhD in 2011, she joins Unison Networks Limited, New Zealand as a Network Investment Specialist.

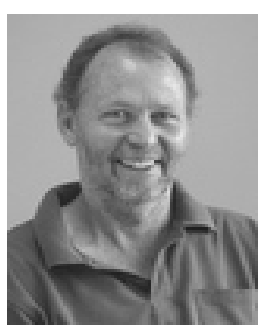

Pat Bodger has BE (Hons) (1972) and PhD (1977) degrees from the University of Canterbury. He has 5 years experience as a design and construction, power station maintenance and commercial engineer with the New Zealand Electricity department. He joined the University of Canterbury, Christchurch, New Zealand in 1982 where he is Chair of Electric Power Engineering and Director of the Electric Power Engineering Centre (EPECentre). 